\title{
Application of Four Phases Teaching Method regarding Care of Labour among Nursing Students and its Effect on their Emotional Intelligence
}

\author{
Heba Sobhy Mohamed Mazen', Samia Abdel Hakeem Hasneen Aboud', Hend Abdallah El- \\ Sayed Afifi ${ }^{3}$ and Zeinb Rabea Abd Elmordy ${ }^{4}$
}

(1) Nursing Specialist in Technical Nursing Institute at Suez University, Suez Governorate, Egypt (2) Professor of Obstetrics and Gynecological Health Nursing, Faculty of Nursing, Benha University, Egypt, (3)Assistant Professor of Obstetrics and Gynecological Health Nursing, Faculty of Nursing, Benha University, Egypt and (4) Lecturer of Obstetrics and Gynecological Health Nursing, Faculty of Nursing, Benha University, Egypt

\begin{abstract}
Background: Four phases teaching method affects emotional intelligence, satisfaction, selfconfidence and practice. Aim of the study: Was to investigate the effect of application of four phase teaching method regarding care of labor among nursing students and its effect on their emotional intelligence. Design: A quasi-experimental study was utilized. Setting: The study was conducted at technical Nursing Institute at Benha University. Sample: A purposive sample included 170 nursing students and divided equally into two groups control and intervention groups. Tools of data collection: Four tools were used, I: A structured interviewing questionnaire, II: Bar-On emotional intelligence Quotient Inventory, III: The student satisfaction and self-confidence in Learning Instrument and tool and IV: Observational check list. Results: The mean scores of emotional intelligence was statistically higher in the intervention group compared to control group $(\mathrm{P} \leq 0.05)$ post implementation of the fourphase teaching method. Also, the intervention group had significant higher scores in satisfaction, selfconfidence and practice compared to control group $(\mathrm{P} \leq 0.05)$. Additionally, there was a positive statistical correlation between total emotional intelligence and total practice scores in both groups $(\mathrm{P} \leq$ 0.05). Finally, it was observed that there was significant positive correlation between emotional intelligence, satisfaction and self-confidence scores among intervention group $(\mathrm{P} \leq 0.05)$. Conclusion: The four-phase teaching method was effective on improving student's emotional intelligence, satisfaction, self-confidence and practice related to care of labour. Recommendations: Replication of the present study with more participants and at several universities for generalization of the results and evaluation the effect of application of four phases teaching method for maternity nursing students on improving labour outcome.
\end{abstract}

Key words: Care of labour, Emotional intelligence, Four-phase teaching method.

\section{Introduction}

The four-phase teaching method were proposed to teach health nursing students. This method is consisted of four phases; demonstration and tell phase is the first phase where the trainer explains the aim of the activity then, trainer performs the needed skills. The second phase is called deconstruction phase where the trainer repeats the intended skills. Comprehension phase is the third step where the trainees should have a true understanding of what being taught and should be able to talk about the skill. Finally, the practice phase where the trainees perform the needed skills in the presence of the trainer so that trainees can be evaluated by trainer (Zamani et al., 2020). 


\section{Application of Four Phases Teaching Method regarding Care of Labour among Nursing Students and its Effect on their Emotional Intelligence}

The four phase teaching methods allow students to learn different skills during a short period of time. Observation and looking are focused in this method. Students' learning happens once observing the needed skills. The main difference in this method compared with the traditional method is that the students work with the real devices. Hence, this method is very good to be applied for the practical and technical courses and increase students' self-confidence and satisfaction (Romero et al., 2018).

Moreover, the four-phase teaching method is a valuable method to improve nursing students' practice to save the mother and child health outcome. The four-phase teaching method in maternity clinical nursing education allows students to actively learn and develop confidence in maternity nursing care without the fear of putting the mother at risk (El-Bana et al., 2021).

One of the chief elements in teaching the health nursing is the methodology of the teaching in the clinical skills. It has been proven that the teacher's personality traits are not as effective as applied teaching method. So that teaching methodology which is known as the key element in students' learning as the four-phase teaching method (Tanner et al., 2017).

Normal labor is the process by which a single mature viable fetus presenting by vertex is expelled from the uterus. The process of labour terminates spontaneously, through birth canal and without any interference, and without any complications for mother or fetus within 24 hours and the four-phase teaching method, on the basis of the findings four-phase could help nursing students to manage the childbirth quite well. The students should be well-informed about managing the childbirth, as a critical part in maternity health nursing (Thornton et al., (2020).
Labor is divided into four stages. The first stage starts from the onset of true labor pains and ends with full dilatations of the cervix. Where the second stage starts from the full dilatation of cervix and ends with expulsion of the fetus from the birth canal. The third stage begins after the expulsion of the fetus and ends with expulsion of the placenta and membranes. Finally, the fourth stage is the stage of early recovery and begins after the expulsion of the placenta and membranes and lasts for one hour to four hours after delivery (Hutchison and Mahdy, 2021).

Emotional intelligence is fundamental for the nursing profession for facilitating the processing of emotional information for motherized and improved mother care through effective communication and therapeutic relationships. Emotional intelligence skills include the ability to demonstrate empathy, self-awareness, motivating students, and demonstrating excellent interpersonal skills (Raghubir, 2018).

Also, emotional intelligence has a great importance to all basic nursing education programs. Nursing students of all ages and diverse backgrounds are engaged in numerous emotionally-charged experiences to learn how to develop a therapeutic relationship by monitoring emotions and those of mothers. Often, nursing students and mothers' experience emotions in respond to precipitating conditions and when students recognize emotions, can adequately address mothers' needs (Dhani and Sharma, 2018).

Hence, emotional Intelligence is manifested in five areas, intrapersonal skills, interpersonal skills, stress management, adaptability, and general mood. The five areas of emotional intelligence have been associated with emerging themes about nursing skills for therapeutic care, interpersonal (empathy, mentoring, collegiality), 


\section{Heba Sobhy, Samia Abdel Hakeem, Hend Abdallah and Zeinb Rabea}

intrapersonal (assertiveness, autonomy, accountability), stress management (self-control), adaptability (persistence, problem-solving), and general mood (happiness with role) (Pouran et al., 2019).

In addition, the role of nurse educator is to prepare students for clinical practice. Three important variables have been selected to be the focus are knowledge, clinical practice and confidence. Nursing knowledge and clinical practice are the basis for undergraduate education and to determine the level of competence with which the new graduate enters the workforce. Therefore, nurse educators must continually identify, implement, and test teaching-learning strategies to promote efficient development of satisfaction, self-confidence and clinical practice of students (Blum and Parcells, 2017).

\section{Significance of the study}

One of the most fundamental clinical skills is management of normal labour which is the most crucial one as a life-saving and the most anxiety provoking for students owing to difficulty. Additionally, the nursing students thought that, training on management of normal labour using traditional methods was not sufficient for students' to be confident and competent in performing skills. This necessitates the introduction of an innovative clinical training approach such as the fourphase teaching method for students to improve practice in skills lab which in turn, could efficiently affect practice in the different clinical settings (Schroeder et al., 2019).

Concerning previous studies of Rani and Yadapadithaya, 2018; El Sayed and Hassan, (2018) and Mohamadirizi et al., (2015) showed that the effectiveness of the four-phase method on the emotional intelligence among nursing students and the positive effect on childbirth. Also, the benefit of emotional intelligence was improving the relationship with humans, improve communication with people, make better empathic skills, manage changes with more confidence, enjoy the work, feeling confident and satisfaction and positive in attitude.

Moreover, to our knowledge, no studies was conducted at the Faculty of Nursing, Benha University about the effect of the fourphase teaching method on emotional intelligence, practice, self-confidence and satisfaction level among nursing students. Therefore, this study was conducted.

\section{Aim of the study}

This study aimed to investigate the effect of application of four phase teaching method regarding care of labor among nursing students and its effect on their emotional intelligence.

\section{Research Hypotheses}

- Nursing students who had received the fourphase teaching method would achieve higher emotional intelligence regarding care of labor than those who didn't.

- Nursing students who had received the fourphase teaching method would achieve high level of practice regarding care of labor than those who hadn't.

- Nursing students who had received the fourphase teaching method would achieve higher satisfaction and self- confidence regarding care of labor than those who didn't.

\section{Subject and methods}

Research design:

Quasi-experimental (pre and posttest) study was followed to fulfill the aim of the study. 


\section{Setting of the study:}

This study was conducted at Technical Nursing Institute, Benha University.

\section{Sampling}

Sample type: A purposive sample.

Sample size: 170 nursing students were included in the current study. The sample size was calculated according to the following formula (Yamane, 1967).

$$
\mathrm{n}=\frac{\mathrm{N}}{1+\mathrm{N}(\mathrm{e})^{2}}
$$

where $\mathrm{N}=$ total population (300 students at academic year 2020/2021), $n=$ required sample size and $\mathrm{e}=$ level of error $=0.05$.

Inclusion criteria: Students in the second year who didn't receive any lectures or training regarding childbirth management in maternal and child-health nursing at classroom and lab or clinical area during first semester at the academic year 2020- 2021.

Exclusion Criteria: Students who were failing in the maternal and child-health nursing course.

\section{Tools of data collection}

Four tools were used for data collection:

\section{Tool I- A structured interviewing questionnaire: -}

It was designed by the researcher after reviewing related literature (Moshki et al., 2017; Azar et al., 2018). It was written in an Arabic language in the form of close and openended question. The questionnaire included data related to students' personal characteristics (age, gender and residence) involved three questions.

\section{Tool II: Bar- On Emotional Intelligence Quotient Inventory:}

This tool was developed by Bar-On (2000) and adapted by the researcher to assess students' emotional intelligence; it consisted of 60 questions divided into five sub domains, Intrapersonal domain, consisted of 15 items. Interpersonal domain, consisted of 12 items. Adaptability domain, consisted of 14 items that involved measuring students' ability to manage. Stress management domain, consisted of 10 items. Finally, General Mood domain, consisted of 9 items.

\section{Scoring system:}

Each item was rated based on three points Likert scale ranging from (3) if the response often, (2) sometimes and (1) rarely. The total score was calculated by the addition of the total scores of all domains; higher score indicated higher emotional intelligence and ranged from (60-180). The total emotional intelligence score was classified as the following: High emotional intelligence: $\geq 60 \%$ of total score (108-180). Low emotional intelligence: $<60 \%$ of total score (60-107)

\section{Tool III: Observational checklist:}

This tool was developed by the researcher after reviewing related literatures (Gabbe et al., 2016 and Lynn, 2015) to assess student's practice and included 10 procedures regarding care of first and fourth stage of labour.

\section{Scoring system:}

Each item in the observational checklist was evaluated as $\mathbf{2}$ score for satisfactory practice and one score for unsatisfactory practice. The total score for the practice was calculated by the addition of the total score of all procedures and ranged from (1-252). The total practice score was classified as the following: Satisfactory practice: $\geq$ $60 \%$ of total score (152-252). Unsatisfactory practice: $<60 \%$ of total score (1-151)

Tool IV: The Student Satisfaction and SelfConfidence in Learning Instrument:

This tool was developed by National League for Nursing (2006) and adapted by the 


\section{Heba Sobhy, Samia Abdel Hakeem, Hend Abdallah and Zeinb Rabea}

researcher to evaluate student satisfaction and self-confidence in learning. It consisted of 5 items that measured student's satisfaction and 8 items that evaluated self-confidence in learning.

\section{Scoring system:}

Each item was given a score based on three points of likert scale ranging from (3) if the response agreed, (2) some extent agree and (1) disagree. The total score of satisfaction and self-confidence were calculated by the addition of the total scores of all items were ranged from (13- 39); higher score indicated higher satisfaction and self-confidence (25-39). The total self-confidence and satisfaction score was classified as the following: High selfconfidence and satisfaction: $\geq 75 \%$ of total score (30-39). Moderate self-confidence and satisfaction $74 \%$ - $50 \%$ of total score (25-29). Low self-confidence and satisfaction: $<50 \%$ of total score (1-24).

\section{Validity of the tools:}

Tools of data collection were reviewed by three panels expertise in the field of Obstetrics and Gynecological Nursing at Faculty of Nursing, Benha University to test content validity and according to their judgment; the questionnaire was modified related to clarity of sentences and appropriateness of contents.

\section{Reliability of the tools:}

The reliability was done by Cronbach's Alpha coefficient test which revealed that; the internal consistency of observational checklist was 0.84; the internal consistency of Bar-on was 0.80 ; the internal consistency of satisfaction and self-confidence was 0.81 .

\section{Ethical considerations:}

Ethical aspects were considered before implementation of the study as the following: The study approval was obtained from Scientific
Research Ethical Committee of faculty of nursing at Benha University before starting the study, The researcher was clarified the aim of the study to each student nurse who participated in the study before applying four-phase of teaching method and starting data collection to gain their confidence and trust. Oral consent was obtained from each student nurse to participate in the study. A letter of approval was sent to the director of Technical Nursing Institute, Benha University included the aim and the setting of the study. The study tools were ensuring that the study didn't touch participant's dignity, culture, traditional and religious aspects and didn't cause any harm for any participant during data collection. Also didn't include any immoral statements and respect human rights. All tools of data collection were burned after statistically analysis to promote confidentiality of the study.

\section{Pilot study:}

A pilot study was carried out on $10 \%$ of sample size (17 students) to assess availability of essential equipment and tools content validity according to statistically analysis of a pilot study and to estimate the time needed for data collection. According to results of the pilot study no modifications were carried out. Thus, students involved in the pilot study were included in the main study sample.

\section{Field work:}

The study was carried out through three months starting from the beginning of October 2020 to the end of December 2020. The researcher visited the previously mentioned setting three days/ week (Saturday, Sunday and Monday) according to schedule table of second year students from $9 \mathrm{Am}$ to $3 \mathrm{Pm}$. The study was conducted through three phases: preparatory, implementation and evaluation.

\section{Statistical analysis:}

Data were verified prior to computerized entry. The Statistical Package for Social 


\section{Application of Four Phases Teaching Method regarding Care of Labour among Nursing Students and its Effect on their Emotional Intelligence}

Sciences (SPSS version 20.0) was used. Descriptive statistics were applied (e.g., mean, standard deviation, frequency and percentages). Tests of significance (chi square, fisher exact test, independent $\mathrm{t}$ test, Pearson correlation and coefficient test) was applied to test the study hypothesis .

- A statistically significant difference was considered at $p$-value $p \leq 0.05$

- A highly statistically significant difference was considered at $\mathrm{p}$-value $\mathrm{p} \leq 0.001$.

\section{Results}

Table (1): Clarifies that $75.3 \%$ of the control group were in the age group of 19 years with a mean age of $19.45 \pm 0.51$ years and $68.2 \%$ of the intervention group were in the age group of 19 years with a mean age of 19.41士 0.52 years. Regarding gender, less than two thirds $62.4 \%$ of the intervention group and three quarters $75.3 \%$ of the control group were female. Moreover, $58.8 \%$ and $51.8 \%$ of the intervention and control groups respectively were from rural areas.

Table (2): Shows that there was no statistically significant difference between mean scores of emotional intelligences in both group before implementation of the four-phase teaching method $(\mathrm{P}>0.05)$. On the other hand, immediately after implementation of the fourphase teaching method showed that the mean scores of emotional intelligence $39.85 \pm 4.21$, $38.36 \pm 3.64,34.61 \pm 2.09,21.18 \pm 3.79,21.32$ \pm 2.04 and $156.74 \pm 10.34$ of students in intervention group compared to control group $33.65 \pm 4.305,33.16 \pm 3.38,31.09 \pm 3.67$, $23.95 \pm 3.59,20.39 \pm 2.73$ and $138.65 \pm 8.91$ regarding intrapersonal, adaptation, interpersonal, stress management, general mood and total score respectively. Also, there was a statistical significance difference between intervention and control groups after implementation of the four-phase teaching method related to emotional intelligence $(\mathrm{P} \leq$ $0.001)$ and $(\mathrm{P} \leq 0.05)$.

Table (3): Illustrates that there was a statistical positive correlation between total emotional intelligence, total satisfaction and total self-confidence scores in the intervention and control groups after implementation of the four-phase teaching method

(Figure (1): Illustrates that more than three quarters $(82.4 \%)$ of the intervention group had high satisfaction in learning compared with $(47.1 \%)$ of the control group P $\leq 0.001)$.

Figure (2): Shows that more than three quarters $(85.9 \%)$ of the intervention group had high self-confidence in learning compared with $(49.4 \%)$ of the control group.

Figure (3): Clarifies that more than three quarters $(77.6 \%)$ of the intervention group had satisfactory practice regarding management of the first and fourth stages of labour compared with $(40 \%)$ of the control group. 
Heba Sobhy, Samia Abdel Hakeem, Hend Abdallah and Zeinb Rabea

Table (1): Frequency distribution of the studied sample in both groups according to general characteristics $(\mathbf{n}=\mathbf{1 7 0})$

\begin{tabular}{|c|c|c|c|c|c|c|}
\hline \multirow{2}{*}{ Variables } & \multicolumn{2}{|c|}{$\begin{array}{c}\text { Intervention group } \\
\mathbf{n}=85\end{array}$} & \multicolumn{2}{|c|}{$\begin{array}{c}\text { Control group } \\
n=85\end{array}$} & \multirow{2}{*}{$\mathbf{X}^{2}$} & \multirow{2}{*}{ P-value } \\
\hline & No & $\%$ & No & $\%$ & & \\
\hline \multicolumn{7}{|l|}{ Age (years) } \\
\hline $19-$ & 58 & 68.2 & 64 & 75.3 & & \\
\hline $20-$ & 27 & 31.8 & 21 & 24.7 & 1.145 & 0.307 \\
\hline Mean \pm SD & \multicolumn{2}{|c|}{$19.41 \pm 0.52$} & \multicolumn{2}{|c|}{$19.45 \pm 0.51$} & $\mathrm{t}=0.322$ & 0.764 \\
\hline \multicolumn{7}{|l|}{ Gender } \\
\hline Male & 32 & 37.6 & 21 & 24.7 & & \\
\hline Female & 53 & 62.4 & 64 & 75.3 & 3.317 & 0.069 \\
\hline \multicolumn{7}{|l|}{ Residence } \\
\hline Rural & 50 & 58.8 & 44 & 51.8 & & \\
\hline Urban & 35 & 41.2 & 41 & 48.2 & $0 . .857$ & 0.355 \\
\hline
\end{tabular}

Table (2): Comparison of mean scores of emotional intelligence between intervention and control groups before and after implementation of the four-phase teaching method $(\mathbf{n}=\mathbf{1 7 0})$

\begin{tabular}{|c|c|c|c|c|c|}
\hline \multirow{2}{*}{\multicolumn{2}{|c|}{ Domains }} & $\begin{array}{l}\text { Intervention group } \\
\qquad \mathrm{n}=85\end{array}$ & $\begin{array}{c}\text { Control group } \\
n=85\end{array}$ & \multirow{2}{*}{$\begin{array}{c}\text { Independent } t \text { - } \\
\text { test }\end{array}$} & \multirow[t]{2}{*}{$P$ value } \\
\hline & & Mean \pm SD & Mean \pm SD & & \\
\hline \multirow[t]{2}{*}{ 1-Intrapersonal } & Before & $31.81 \pm 4.18$ & $31.82 \pm 4.36$ & 0.018 & 0.986 \\
\hline & After & $39.85 \pm 4.21$ & $33.65 \pm 4.305$ & 9.492 & $0.000 * *$ \\
\hline \multirow[t]{2}{*}{ 2- Adaptation } & Before & $30.68 \pm 3.79$ & $31.49 \pm 4.46$ & 1.278 & 0.203 \\
\hline & After & $38.36 \pm 3.64$ & $33.16 \pm 3.38$ & 9.668 & $0.000 * *$ \\
\hline \multirow[t]{2}{*}{ 3- Interpersonal } & Before & $29.64 \pm 3.58$ & $29.76 \pm 4.79$ & 0.199 & 0.842 \\
\hline & After & $34.61 \pm 2.09$ & $31.09 \pm 3.67$ & 7.676 & $0.000 * *$ \\
\hline \multirow{2}{*}{$\begin{array}{l}\text { 4-Stress } \\
\text { management }\end{array}$} & Before & $22.32 \pm 5.29$ & $21.73 \pm 4.02$ & 0.831 & 0.407 \\
\hline & After & $21.18 \pm 3.79$ & $23.95 \pm 3.59$ & 4.883 & $0.000 * *$ \\
\hline \multirow[t]{2}{*}{ 5- General mood } & Before & $18.78 \pm 2.21$ & $18.47 \pm 2.45$ & 0.857 & 0.393 \\
\hline & After & $21.32 \pm 2.04$ & $20.39 \pm 2.73$ & 2.544 & $0.012 *$ \\
\hline \multirow[t]{2}{*}{ Total score } & Before & $133.23 \pm 11.78$ & $133.28 \pm 13.34$ & 0.124 & 0.891 \\
\hline & After & $156.74 \pm 10.34$ & $138.65 \pm 8.91$ & 11.559 & $0.000 * *$ \\
\hline
\end{tabular}

*A statistically significant difference $(\mathrm{P} \leq 0.05) \quad \mathrm{t}=$ independent $\mathrm{t}$ test $\quad * *$ A high statistically significant difference $(\mathrm{P} \leq 0.001)$. 


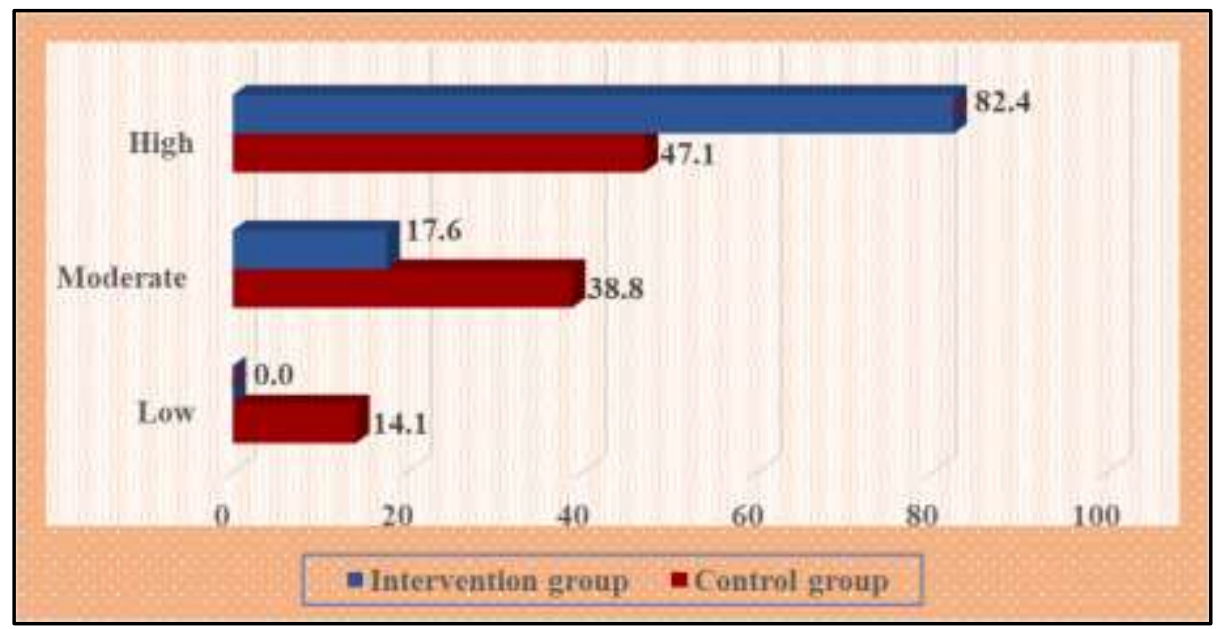

FET $=79.564 \& \mathrm{P}=0.000$

Figure (1) Frequency distribution of the studied sample in both groups according to level of satisfaction in learning $(n=170)$.

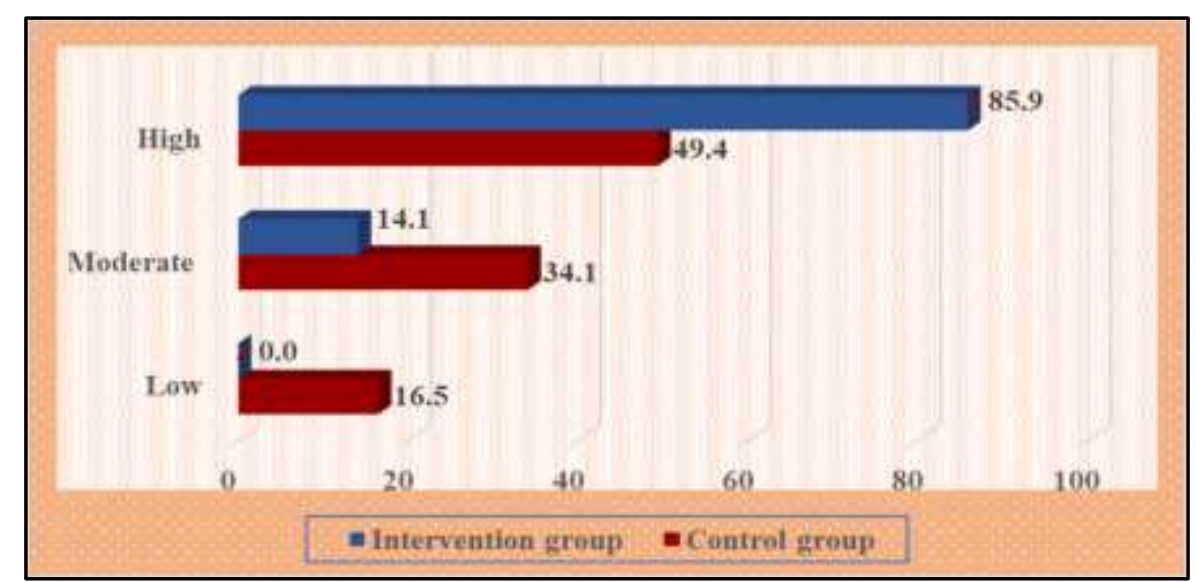

FET $=28.780 \& \mathrm{P}=0.000$

Figure (2) Frequency distribution of the studied sample in intervention and control groups according to level of self-confidence in learning $(n=170)$.

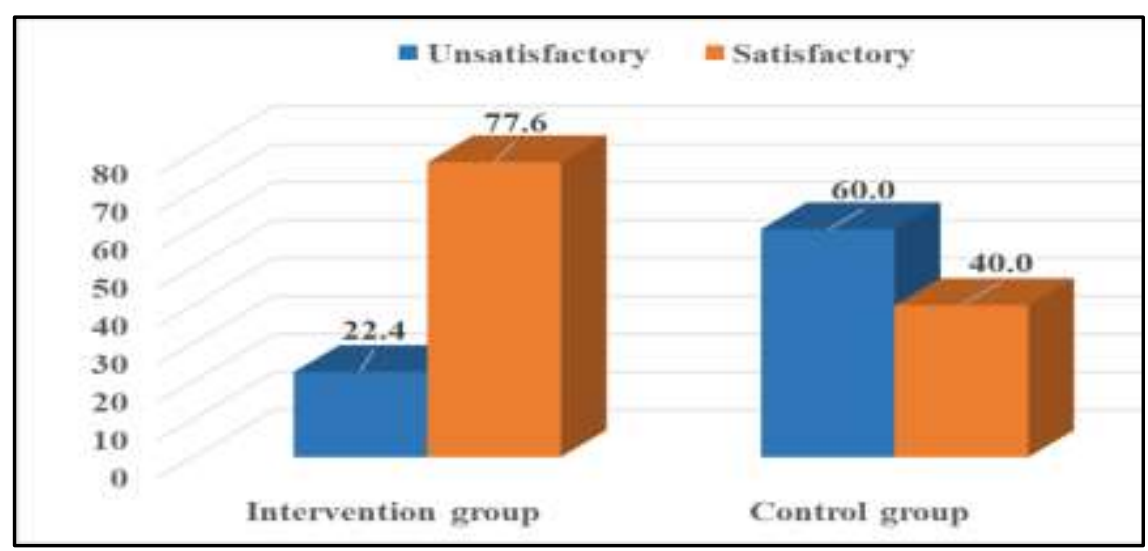

Figure (3): Frequency distribution of the studied sample in intervention and control groups according to total level of practice during first and fourth stage of labour $(n=170)$. 
Table (3): Correlation between the studied sample in intervention and control groups regarding total emotional intelligence, total satisfaction and total self-confidence scores after implementation of the four-phase teaching method $(n=170)$

\begin{tabular}{||l|c|c|c|c|}
\hline \multirow{2}{*}{\multicolumn{1}{|c|}{ Variables }} & \multicolumn{4}{|c|}{ Total emotional intelligence score } \\
\cline { 2 - 5 } & Intervention group & \multicolumn{2}{c|}{ Control group } \\
\cline { 2 - 5 } & $\mathbf{r}$ & $\mathbf{p}$ & $\mathbf{r}$ & $\mathbf{p}$ \\
\hline Total satisfaction score & 0.259 & $0.017^{*}$ & 0.379 & $0.002^{* *}$ \\
\hline Total self-confidence score & 0.399 & $0.000^{* *}$ & 0.438 & $0.000^{* *}$ \\
\hline
\end{tabular}

**A high statistically significant difference $(\mathrm{P} \leq 0.001$

\section{Discussion}

The application of the four-phase teaching method is thought to improve nursing students' practice thus preventing complications and improve the outcomes of pregnancy and delivery for mothers and newborns (Van de Ven, 2017).

The application of the four-phase teaching method for nursing students during labor was expected to improve labor outcome and increase nursing students' level of satisfaction, self-confidence and emotional intelligence. In addition, nursing is a stressful profession due to requirements of mother's care which requires a high degree of self-confidence and emotional intelligence. Hence, emotional intelligence is required to help nursing students to control emotions; as the inability to control emotions can lead to increase anxiety, stress and negatively affect the quality of nursing care (Giacomino et al., 2020).

The present study was aimed to investigate the effect of application of four- phase teaching method regarding care of labour among nursing students and its effect on emotional intelligence.

The findings of the current study will be presented under four main sections include: demographic characteristics of the studied sample; nursing students' emotional intelligence, nursing students' self-confidence and satisfaction and nursing students' practice regarding the four-phase teaching method, and correlation between emotional intelligence, satisfaction, self-confidence, and practice scores after implementation of the four-phase teaching method.

As regards demographic characteristics of the studied nursing students, the results of the present study showed that three quarters of the control group were in the age group of 19 years with a mean age of $19.45 \pm 0.51$ years and more than two thirds of the intervention group were in the age group of 19 years with a mean age of $19.41 \pm 0.52$ years. Also, there was no significant difference found between the intervention and control groups related to age. This result is nearly similar to Awad and Mohamed, (2018) who studied " Effectiveness of Peyton's four-step approach on nursing students' practice in skill-lab training" on 48 students and found that the mean age of the studied students was $19.5 \pm 1.5$ years and there was no significant difference between the intervention and control groups related to age.

On the other hand, this result is contradicted with $\mathbf{O h}, \mathbf{( 2 0 1 7 )}$ who conducted a study to determine "the effects of simulationbased training on the learning outcome of nursing students" and found that the mean age was 21.44 years old; more than half $65.72 \%$ of the students were aged 21 years old. 


\section{Application of Four Phases Teaching Method regarding Care of Labour among Nursing Students and its Effect on their Emotional Intelligence}

Concerning gender of the studied nursing students, the result of the current study revealed that less than two thirds of the intervention group and three quarters of the control group were female. This result is nearly in the same line with Galal et al., (2018) who studied "effect of Simulation on Maternity Nursing Students' Perception, Satisfaction and Self-Confidence Regarding student's satisfaction and self-confidence in learning" and showed that more than three quarters of the students were females and there was no significant difference between the intervention and control groups related to gender.

Additionally, the study findings are in agreement with Ahmed et al., (2018) who studied" Effect of Payton's Four Step Approach on Skill Acquisition, Self-Confidence and SelfSatisfaction among Critical Care Nursing Students" on 78 students, at Alexandria University, and showed that $69.2 \%$ of students in both groups were females. Also, there was no significant difference was found between the intervention and control groups related to gender.

Regarding residence of the studied nursing students, the result of the current study showed that more than half of the intervention and control groups were from rural areas and there was no statistically significant difference between both groups related to residence. This result is nearly similar to a study conducted by Krautter et al., (2015) who studied" Peyton's four-step approach: differential effects of single instructional steps on procedural and memory practice- a clarification study" on 97 students and found that there was no statistically significant difference with regard to residence.

Concerning total nursing students' emotional intelligence regarding the four-phase teaching method, the result of the present study revealed that there was no statistically significant difference between mean scores of emotional intelligences in both group before implementation of the fourphase teaching method, while there was a statistically significant difference between both groups after implementation of the four-phase teaching method. Mean scores of emotional intelligence domains (intrapersonal, adaptability, interpersonal, general mood and stress management) were higher in intervention group compared to control group. This result may be due to the positive effect of the four-phase teaching method, the learning sessions and simple explanations that was given to students. So, nursing students were very interested and satisfied during the learning sessions.

This result is similar to a study performed by Mohamadirizi et al., (2015) who studied "The effect of four-phase teaching method on midwifery students' emotional intelligence in managing childbirth" at Isfahan University on 30 midwifery students and found that the findings of the independent t-test did not show any significant difference between emotional intelligence scores of the experimental and the control group before the intervention, whereas a statistically significant difference was observed after the intervention between the scores of two groups $(\mathrm{P}=0.009)$.

Moreover, Albagawi, (2018) who conducted a study to evaluate " Emotional Intelligence among the Fourth Year Nursing Students: A cross-sectional study" on 72 nursing students found that the overall level of emotional intelligence of the nursing students was high after teaching. This result may be due to using of effective teaching strategies that enhance emotional intelligence competencies among nursing students during academic education and to the clinical teaching effectiveness.

On the other hand, this result is contradicted with Farahaniet et al., (2017) 


\section{Heba Sobhy, Samia Abdel Hakeem, Hend Abdallah and Zeinb Rabea}

who studied" Investigating the effect of education on baccalaureate nursing students' emotional intelligence scores" on 69 first-year nursing students and the findings revealed no significant differences between the two study groups in terms of emotional intelligence scores before or after the intervention. Also, Rappold, (2017) who studied "The effect of nursing education on emotional intelligence scores" found that there was no statistically significant difference between the two groups in term of emotional intelligence scores before and after intervention.

Concerning nursing students' satisfaction and self-confidence in learning regarding the four-phase teaching method, the finding of the current study illustrated that there was a highly statistical significance difference between intervention and control groups after implementation of the four-phase teaching method related to satisfaction and self-confidence in learning. Also, the level of satisfaction and self-confidence was higher in intervention group compared to control group. This result may be due to the positive effect of the four- phase teaching method and the learning sessions.

This result is similar to the study performed by El-Sayed and Hassan, (2018) and found that the students of the intervention group had a significant higher score of all items of self-confidence and satisfaction in learning compared to control group. Also, this result is similar to Ahmed and Mohamed, (2017) and found that sim-lab as a clinical teaching strategy is effective on enhancing students' satisfaction and level of self-confidence.

In addition, Awad and Mohamed, (2018) who studied" Effectiveness of Peyton's fourstep approach on nursing students' practice in skill-lab training" and assumed that the group of trainees who were instructed by Peyton's four-step approach increased self-confidence and satisfaction of the training sessions.

Moreover, the study findings are in agreement with El-Bana and Abd El hakam, (2018) who studied "the effect of simulationbased training on maternity nurses 'practice and self-confidence regarding primary post-partum hemorrhage management" and found that there was a highly statistically significant difference between studied nursing students' selfconfidence pre- and post-intervention.

Also, Omer (2017) who studied" Nursing Students' Perceptions of Satisfaction and SelfConfidence with Clinical Simulation Experience" On 117 students showed that the students were satisfied with learning and that the clinical simulation session improved up self-confidence and the students indicated high satisfaction and self-confidence because the methods used in simulation were effective and give clear ideas of what was expected from students.

On the other hand, this result is contradicted with Sopka, (2017) who studied "The students' self-confidence using questionnaires concerning the knowledge of basic life support algorithm and external chest compression practice before and after training using media-supported 4-step approach". The result revealed that no significant difference was found between the students' confidence before and after the application of the fourphase teaching method ( $\mathrm{p} \geq 0.05)$.

Also, Galal et al., (2018) showed that less than half of the students had moderate level of satisfaction in learning towards simulation activities and less than half of the students had high level of self-confidence in learning regarding simulation activities.

Nursing students' practice during labour, aimed to ensure the best possible outcome for the mother and the newborn. So, nursing care should focus on establishing meaningful, open 


\section{Students and its Effect on their Emotional Intelligence}

relationship, determining the fetal status and encouraging the mother's self-direction and also supporting the mother and the family throughout the labor and birth process. Furthermore, caring of a mother during labor includes support of normal, physiologic changes as well as the anticipation of timely response to potential complications as postpartum hemorrhage (Benfield et al., 2018).

Regarding nursing students' practice during first and fourth stage of labour after implementation of the four-phase teaching method, the result of the current study showed that more than three quarters of the studied students had satisfactory practice regarding labour and there was a highly statistical significance difference between intervention and control groups after implementation of the four-phase teaching method.

This result may be due to nursing students' interest about the training and the positive effect of the four -phase teaching method. Also, during the training courses, the students are given a chance of being in real situations; therefore, they can learn the clinical duties better. Hence, high emotional intelligence would help students to make the best decision in providing help in the nursing and midwifery. Also, this result could be interpreted that effective teaching method reflected on practice and indicates the importance of the four-phase teaching method and continuous education for nursing students on improving practice regarding labour.

This result agrees with Habib et al., (2017) who studied" "Designing, Implementing and Evaluating Preclinical Simulation Lab for Maternity Nursing Course" and found that the students agreed that simulation assisted in understanding how the clinical practice improved and helped students in building skill $(\mathrm{m}=3.92$, $\mathrm{SD}=0.91)$.
Also, this result is similar to the study performed by El-Sayed and Hassan (2018) and found that there was a highly statistically significant improvement of practice in learning compared to control group after intervention.

Additionally, this finding agrees with Mohamadirizi et al., (2015) and found that the mean scores of the students regarding practice increased after intervention $(\mathrm{p} \leq 0.05)$.

Regarding correlations between the studied nursing students' total emotional intelligence, total satisfaction and total selfconfidence scores, the finding of the current study illustrated that there was a positive statistically correlation between total emotional intelligence, total satisfaction and total selfconfidence scores in the intervention and control groups after implementation of the four-phase teaching method. This may be due to that the students with high emotional intelligence had high level of satisfaction and self-confidence in learning.

This result is in the same line with Shamsaei et al., (2017) who studied "Relationship Between Emotional Intelligence and Self-Confidence in Bachelor Students of Nursing and Midwifery Schools in Hamadan" and found that there was a positive significant relationship between emotional intelligence and self-confidence and satisfaction (P < 0.001).

Also, Abo El Fetouh (2019) who studied" Relationship between emotional intelligence and self-esteem among nursing students" on 400 nursing students and revealed that the relation between nursing student's level of emotional intelligence with level of selfesteem, showed a positive statistically significant relation between the level of emotional intelligence with the level of selfesteem among students. In addition, Özer et al., (2016) who studied "the relationship 


\section{Heba Sobhy, Samia Abdel Hakeem, Hend Abdallah and Zeinb Rabea}

between emotional intelligence and satisfaction of college students" showed significant relations between emotional intelligence and satisfaction.

In contrast, Bibi et al., (2016) who studied" Relationship between Emotional Intelligence and Self Esteem among Pakistani University Students" on 250 nursing students and found that there was no significant difference regarding self-esteem among Pakistani university students.

\section{Conclusion}

The four-phase teaching method was highly significantly more effective than lecture regarding student's emotional intelligence domains (intrapersonal, adaptability, interpersonal, general mood and stress management), satisfaction, self-confidence and practice related to care of the first and fourth stages of labour. Also, the student's satisfaction, self-confidence, and practice were statistically significantly higher among intervention group compared to control group. In addition, Moreover, there was a positive statistically correlation between total emotional intelligence score, total satisfaction and total self-confidence scores in both groups after implementation of the four-phase teaching method. Also, there was a positive statistical correlation between total emotional intelligence score and total practice score in both groups after implementation of the four-phase teaching method and there was a positive statistically correlation between total practice, total satisfaction and total selfconfidence in both groups after implementation of the four-phase teaching method. Therefore, the aim was achieved and the study hypotheses were supported.

\section{Recommendations}

- Integration of four- phase teaching method in curriculum development at obstetrics and gynecology nursing.
- Replication of the present study with more participants and at several universities for generalization of the results.

\section{Further study need to be performed:}

- Evaluate the effect of application of four phase teaching method for maternity nursing students on improving labour outcome.

- Effect of the four-phase teaching method on maternity nursing student's skill related to emergency procedures and its effect on satisfaction and self-confidence.

\section{References}

Abo El Fetouh S.M., (2019). Relationship between emotional intelligence and self-esteem among nursing students, Egyptian Nursing Journal; 16 (2): 53-58.

Ahmed E., and Mohamed M., (2017). Effect of sim-lab versus traditional lab training on maternity nursing students' satisfaction and self-confidence IOSR Journal of Nursing and Health Science; 5 (2):108-115.

Ahmed F.R., Morsi S.R., and Mostafa H.M., (2018). "Effect of Payton's Four Step Approach on Skill Acquisition, Self-Confidence and SelfSatisfaction among Critical Care Nursing Students." IOSR Journal of Nursing and Health Science (IOSR-JNHS); 7 (6): 38-47.

Albagawi B., (2018). Emotional Intelligence Among the Fourth Year Nursing Students: A cross-sectional study, Advances in social science research Journal; 5 (11), 561-569.

Awad S.A., and Mohamed M.H.N., (2018). Effectiveness of Peyton's four-step approach on nursing students' practice in skill-lab training, Journal of Nursing Education and Practice; 9 (5).

Azar J., Schmalz M.C., and Tecu I., (2018). Anticompetitive effects of common ownership. The Journal of Finance; 73 (4), 1513-1565. 
Bar-on R., and Parker J.D.A., (2000). The handbook of emotional intelligence: Theory, Development, Assessment, and Application at home, school and in the workplace. San Francisco: Jossey-Bass Hardback.

Benfield R., Heitkemper M.M., and Newton E.R., (2018). Culture, bathing and hydrotherapy in labor. An exploratory descriptive pilot study. Midwifery; 64: 110114.

Bibi S., Saqlain S., Mussawar B., (2016). Relationship between Emotional Intelligence and Self Esteem among Pakistani University Students. J Psychol Psychother 6: 279. doi: 10.4 .

Blum C.A., and Parcells D., (2017). HighFidelity Nursing Simulation: Impact on Student Self-Confidence and Clinical Competence, International Journal of Nursing Education Scholarship; 7(1), Art., 18.

Dhani P., and Sharma T., (2018). Emotional Intelligence and Personality Traits as Predictors of Job Practice of IT Employees. International Journal of Human Capital and Information Technology Professionals (IJHCITP); 9 (3): 70-83.

El-Bana M.M., Kesten K.S., and Blakely J., (2021). Educational characteristics and content of postgraduate nurse practitioner residency/fellowship programs. Journal of the American Association of Nurse Practitioners; 33 (2): 126-132.

El-Bana H.M., and Abd Elhakm M.A., (2018). Effect of Simulation Based Training on Maternity Nurses' Practice and Self-confidence Regarding Primary Postpartum Hemorrhage Management. American Journal of Nursing Research; 6 (6), 388-397. DOI: 10.12691/ajnr-66-6.

El-Sayed H.E.M., and Hassan S., (2018). Application of Four Phase Teaching Method Regarding Care of the First Stage of Labour among Nursing Students and Effect on Their Emotional Intelligence, International Journal of Novel Research in Healthcare and Nursing; 5 (2), PP: (31-41).

Farahaniet M.A., Kelishami F.G., Orak R.J., and Naimeh Seyedfatemi N., (2017). Investigating the effect of emotional intelligence education on baccalaureate nursing students' emotional intelligence scores. Nurse Education in Practice.

Gabbe S.G., Niebyl J. R., Simpson J.L., Landon M.B., Galan H. L., Jauniaux E. R., and Grobman W.A., (2016). Obstetrics. normal and problem pregnancies e-book. Elsevier Health Sciences.

Galal A.E., Marwa A.A., Soad A.R., and Hend A.E., (2018). Effect of Simulation on Maternity Nursing Students' Perception, Satisfaction and Self-Confidence. Egyptian Journal of Health Care, EJHC; 9 (3): 14-26.

Giacomino K., Caliesch R., and Sattelmayer K.M., (2020). The effectiveness of the Peyton's 4-step teaching approach on skill acquisition of procedures in health professions education: A systematic review and meta-analysis with integrated meta-regression. Peer J.; 8: e10129.

Habib, ALFozan, Haya, El Sayed, Yousria and Farida (2017). Designing, Implementing and Evaluating Preclinical Simulation Lab for Maternity Nursing Course. Journal of Education and Practice; 6 (12), P: 152-161.

Hutchison J., and Mahdy H., (2021). Stages of Labor. In: StatPearls. Treasure Island (FL): Stat Pearls Publishing, PP: 223-233.

Krautter M., Dittrich R., Safi A., Krautter J., Maatouk I., Moeltner A., Herzog W., and Nikendei C., (2015). Peyton's four-step approach: differential effects of single instructional steps on procedural and memory practice - a clarification study. Adv Med Educ Pract.; 6: 399-406. doi:10.2157/AMEP.S81923. 


\section{Heba Sobhy, Samia Abdel Hakeem, Hend Abdallah and Zeinb Rabea}

Lynn H.K., (2015). Professionalism in the Business School Curriculum (Doctoral dissertation, Ritsumeikan Asia Pacific University).

Mohamadirizi S, Fahami F, Bahadoran P\& Ehsanpour S (2015). The effect of four-phase teaching method on midwifery students' emotional intelligence in managing the childbirth, J Educ Health Promot; 4: 47. Reterived, (2020).

Moshki M., Dehnoalian A., \& Alami A., (2017). Effect of precede-proceed model on preventive behaviors for type 2 diabetes mellitus in high-risk individuals. Clinical nursing research; 26(2), 241-253.

National League for Nursing, (2006). Summary report: Designing and implementing models for the innovative use of simulation to teach nursing care to ill adults and children: A national, multisite, multi-method study.

Oh Y., (2017). Effects of Simulation-based training on the learning outcome of Nursing Students. CIN: Computers, Informatics, Nursing, 32, 84-89.

Omer T., (2017). Nursing Students' Perceptions of Satisfaction and SelfConfidence with Clinical Simulation Experience. Journal of Education and Practice; 7 (5).

Özer E., Hamarta E., and Deniz M. E., (2016). Emotional Intelligence, Core-Self Evaluation, and Life Satisfaction. Psychology; 7: 145-153.

Pouran R., Hamed Z., and Tiba M., (2019). Relationship between communication skills and emotional intelligence among nurses, RCN Publishing Company. doi.10.7748/nm, e1820.

Raghubir A.E., (2018). Emotional intelligence in professional nursing practice: A concept review using Rodgers's evolutionary analysis approach. International journal of nursing sciences; 5 (2): 126-130.

Rani P. B., and Yadapadithaya P. S. (2018). Conquering workplace stress through emotional intelligence: strategies and possibilities. Indian Journal of Commerce and Management Studies; 9 (1): 7-12.

Rappold S.M., (2017). The effect of nursing education on emotional intelligence scores. Graduate Student Theses, Dissertations, \& Professional Papers. 11114.

Romero P., Günther P., Kowalewski K.F., Friedrich M., Schmidt M.W., Trent S.M., De La Garza J.R., Müller-Stich B.P., and Nickel F., (2018). Halsted's "See One, Do One, and Teach One" versus Peyton's Four-Step Approach: A Randomized Trial for Training of Laparoscopic Suturing and Knot Tying. J Surg Educ.; 75 (2): 510-515.doi: 10.1016/j. jsurg.

Schroeder H., Henke A., Stieger L., Beckers S., Biermann H., Rossaint R., and Sopka S., (2019). Influence of learning styles on the practical performance after the four-step basic life support training approach. An observational cohort studies. PLoS ONE; 12 (5): $1-9$.

Shamsaei F., Foad Yousefi F., and Sadeghi A., (2017). Relationship Between Emotional Intelligence and Self-Confidence in Bachelor Students of Nursing and Midwifery Schools in Hamadan. Avicenna Journal of Neuro Psych Physiology; 8(1).

Sopka S., (2017). The students' self-confidence using questionnaires concerning the knowledge of basic life support algorithm and external chest compression practice before and after training using media-supported 4-step approach. Scandinavian Journal of Trauma Resuscitation and Emergency Medicine; 20 (1): 37. 
Tanner K.D., Chatman L., and Allen D., (2017). Approaches to biology teaching and learning: Science teaching and learning across the school-university divide-cultivating conversations through scientist-teacher partnerships. Cell Biology Education; 2 (4): 195-201.

Thornton J.M., Browne B., and Ramphul M., (2020). Mechanisms and management of normal labour, Obstetrics, Gynecology and Reproductive Medicine; 30 (3): 84-90.

Van de Ven A.H., (2017). The innovation journey: you can't control it, but you can learn to maneuver it. Innovation; 19 (1), 39-42.
Yamane and Taro., (1967). Statistics, An Introductory Analysis, 2nd Ed., New York: Harper and Row.

Zamani M., Nasr-Esfahani M., Forghani M., Sichani M.A., and Omid A., (2020). Endotracheal intubation training to medical practitioners: Comparison of the modified 4step Payton's training method and Halsted's training method in a simulated environment. J Educ Health Promot.; 9: 126.doi: 10.4103/jehp.jehp_705_19. 
تطبيق طريقة التدريس علي أربع مراحل لرعاية الولادة لطالبات التمريض وتاثيرها على الذكاء العاطفي هبة صبحي ححم مازن- سامية عبد الحكيم حسانين عبود- هند عبد الله السيد عفيفي - زينب ربيع عبدالمرضي

تعد طريقة التدريس رباعية المراحل ذات قيمة لتحسين الذكاء العاطفي لطلاب التمريض ورضاهم وثتتهم بأنفسهم وممارساتهم للحفاظ على صحة الأم و الطفل ويجب أن يكون لدي طالب التمريض الثقة لبناء

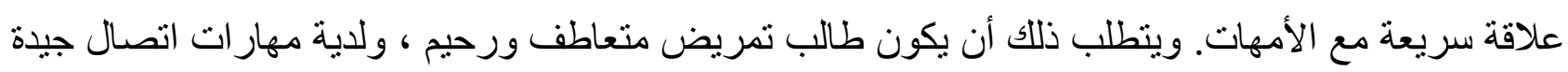
وتحفيز ولطف ويجب أن يتمتع طالب التمريض أيضًا بدرجة من الثقة بالنفس ومعلومات حديثة ولديه شعور

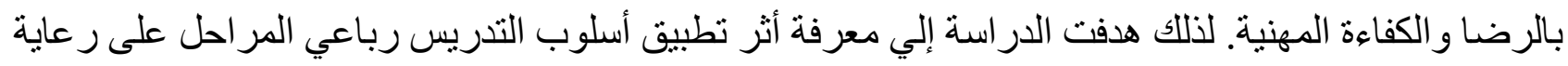

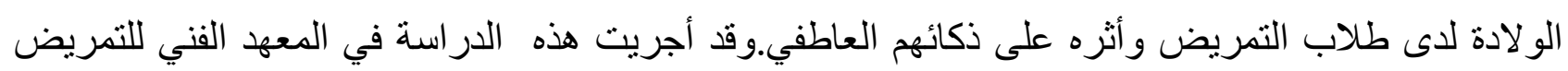
جامعة بنها علي · V طالب تمريض. حيث كثفت النتائج عن أن هناك فرق دلالة إحصائية عالية بين

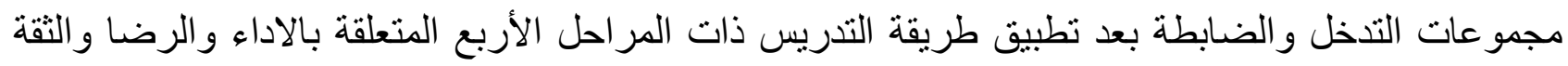
بالنفس في التعلم. كما أوضحت الدراسة أن هناك علاقة إحصائية إيجابية بين مجموع درجات الذكاء العاطفي

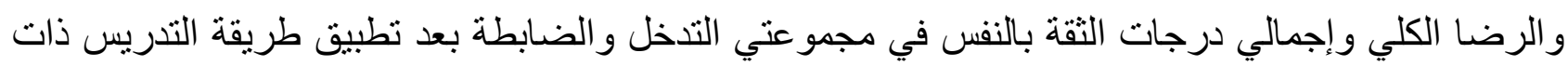

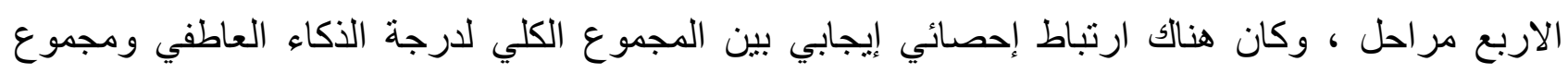

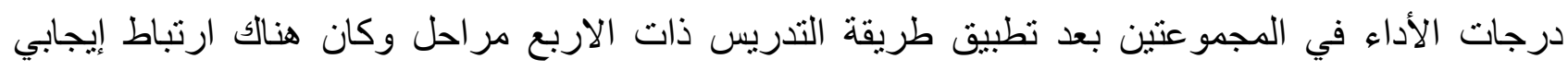

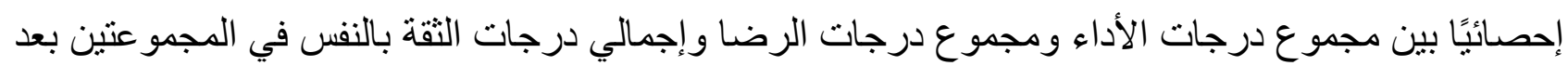

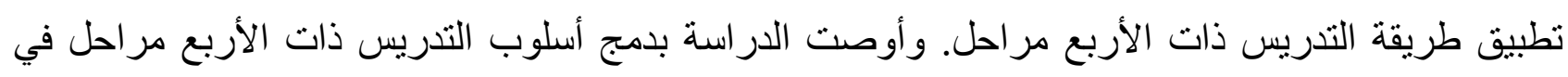

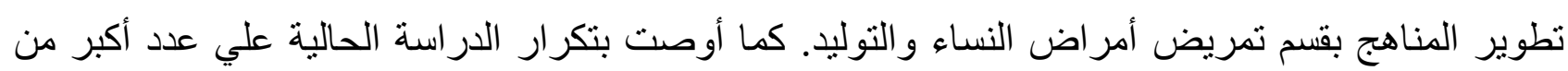
المشاركين وفي عدة جامعات لتعميم النتائج. 